\title{
Facility Siting as a Decision Process at the Savannah River Site
}

by

L. D. Wike

Westinghouse Savannah River Company

Savannah River Site

Aiken, South Carolina 29808

A document prepared for FOR RELEASE TO THE CITIZENS ADVISORY BOARD at from ? - ?.

DISTRIBUTON OF FIIS DOCUMENT IS UNUMTTEO at
DOE Contract No. DE-ACO9-89SR18035

This paper was prepared in connection with work done under the above contract number with the U.S.

Department of Energy. By acceptance of this paper, the publisher and/or recipient acknowledges the U.S. Government's right to retain a nonexclusive, royalty-free license in and to any copyright covering this paper, along with the right to reproduce and to authorize others to reproduce all or part of the copyrighted paper.

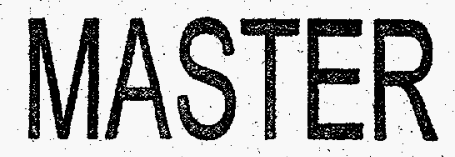





\section{DISCLAIMER}

Portions of this document may be illegible in electronic image products. Images are produced from the best available original document. 

Derivative Classifier

\section{Facility Siting as a Decision Process at The Savannah River Site (U)}

Vestinghouse Savannah River Company

avannah River Site

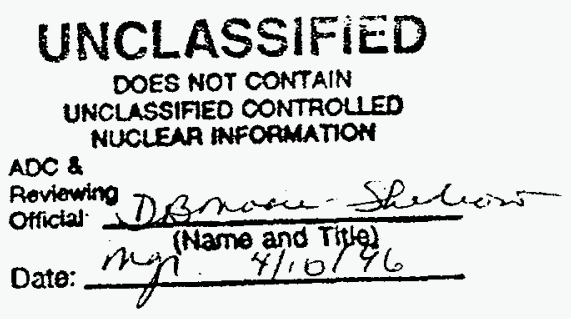

wiken, SC 19808

repared for the U.S. Department of Energy under contract no. DE-AC09-89SR18035 


\section{DISCLAIMER}

This report was prepared as an account of work sponsored by an agency of the United States Government. Neither the United States Government nor any agency thereof, nor any of their employees, makes any warranty, express or implied, or assumes any legal liability or responsibility for the accuracy, completeness, or usefulness of any information, apparatus, product, or process disclosed, or represents that its use would not infringe privately owned rights. Reference herein to any specific commercial product, process, or service by trade name, trademark, manufacturer, or otherwise does not necessarily constitute or imply its endorsement, recommendation, or favoring by the United States Government or any agency thereof. The views and opinions of authors expressed herein do not necessarily state or reflect those of the United States Government or any agency thereof.

This report has been reproduced directly from the best available copy.

Available to DOE and DOE contractors from the Office of Scientific and Technical Information, P.O. Box 62, Oak Ridge, TN 37831; prices available from (615) 576-8401.

Available to the public from the National Technical Information Service, U.S. Department of Commerce, 5285 Port Royal Road, Springfield, VA 22161. 
Table of Contents

Introduction

Recent Facility Siting at SRS

Basis for Facility Siting Methodology

Standardization of the Site Selection Process

References

Appendix A

List of Figures

Figure 1. Generalized flow diagram of the site selection process.

6 
WSRC-RP-95-664

Rev 0

June 19.1995

Facility Siting as a Decision Process at The Savannah River Site (U)

Lynn D. Wike

Savannah River Technology Center

Westinghouse Savannah River Company

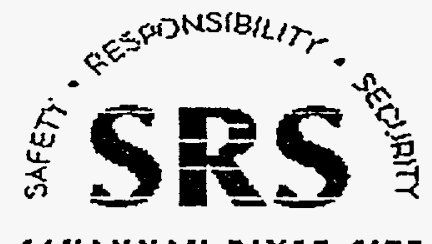

Prepared for the U.S. Department of Energy under contract no. DE-AC09-89SR18035 


\section{Facility Siting as a Decision Process at The Savannah River Site (U)}

June 19, 1995

Lynn D. Wike

Savannah River Technology Center

Westinghouse Savannah River Company

\section{Introduction}

Site selection for new facilities at Savannah River Site (SRS) historically has been a process dependent only upon specific requirements of the facility. While this approach is normally well suited to engineering and operational concerns, it can have serious deficiencies in the modern era of regulatory oversight and compliance requirements. There are many issues related to the site selection for a facility that are not directly related to engineering or operational requirements; such environmental concerns can cause large schedule delays and budget impacts, thereby slowing or stopping the progress of a project. Some of the many concerns in locating a facility include: waste site avoidance, National Environmental Policy Act requirements, Clean Water Act, Clean Air Act, wetlands conservation, U. S. Army Corps of Engineers considerations, U. S. Fish and Wildlife Service statutes including threatened and endangered species issues, and State of South Carolina regulations, especially those of the Department of Health and Environmental Control. In addition, there are SRS restrictions on research areas set aside for National Environmental Research Park (NERP), Savannah River Ecology Laboratory, Savannah River Forest Station, University of South Carolina Institute of Archaeology and Anthropology, Southeastern Forest Experimental Station, and Savannah River Technology Center (SRTC) programs. As with facility operational needs, all of these siting considerations do not have equal importance. The purpose of this document is to review recent site selection exercises conducted for a variety of proposed facilities, develop the logic and basis for the methods employed, and standardize the process and terminology for future site selection efforts.

\section{Recent Facility Siting at SRS}

The Environmental Sciences Section (ESS) of SRTC has been involved in a number of site selection exercises in the recent past including those for the New Production Reactor (NPR), Nuclear Weapons Complex Reconfiguration Site (NWCRS), Replacement Power Facility (RPF), and New Sanitary Landfill (NSL).

The technical evaluation of potential NPR sites was probably the first formal multidisciplinary site selection exercise of its kind at SRS (Bean and Olson, 1990). The evaluation and resultant document were the product of a committee comprised of representatives from eight different organizations within Westinghouse Savannah River Company. The committee acted by consensus using available technical information and best professional judgment to establish disqualifying conditions to screen the SRS for suitable areas and select candidate sites, and to define and group site selection criteria for the comparative evaluation of the potential sites. The groups and individual criteria were assigned values and weights by which each of the candidate sites were scored. The category scores were totaled to provide final comparison values for each site. The basic 
process by which the NPR site selection exercise proceeded has served as a basis for subsequent site selection exercises.

The NWCRS site selection was part of a much larger effort to provide a proposal (DOE SRFO, 1991) in response to the Invitation for Site Proposals for the Nuclear Weapons Complex Reconfiguration Site (US DOE, 1991). Even though the NWCRS exercise was not a site selection in the same sense as the others, it used the same methodology as developed in the NPR site selection exercise. This process was utilized to screen the entire SRS for an area of sufficient size and suitable attributes to be offered for the relocation of other DOE weapons complex operations. The process provided very satisfactory results.

The RPF site selection (Wike et. al, 1992) was a straight forward exercise in finding a suitable location for a proposed coal-fired steam and power generating facility. In this exercise, the flexibility of the site selection process proved to be of great value. The process itself was refined during this particular exercise as newer technologies in information gathering and presentation became available. Even though it appears that a decision has been made to not build the RPF, the site selection exercise proved to be of benefit in further definition and understanding of the site selection process.

\section{Basis for Facility Siting Methodology}

The site selection process at SRS is based on a hybrid of several different techniques. Previous site selection methods manifest elements of four different processes: normal interactive group decision making, Nominal Group Technique, Delphi Technique, and Decision Analysis.

Normal interactive group decision making, for lack of a specific name, is the standard group decision making process as practiced at SRS and throughout government and business. It may be called a task team, committee, or working group, but the process is the same. Representatives from organizations with a specific interest in a given project interact to address project problems and concerns relevant to their group. The members of this group will then interact with their own organization and report back to the group at its next meeting. This iterative process can be very successful, but its efficiency seems to be inversely related to group size. That is to say that as the group gets larger, or the magnitude of the issue at hand increases, the efficiency and success of this method appears to decrease. This method is also vulnerable to arbitrary or politically driven decisions. This method is generally used for what is often referred to as a routine meeting where the group agrees on a goal, has the means to achieve that goal and the process is generally leader - centered (Delbec et al. 1975). It is not well suited to the needs of land use or site selection exercises.

The Nominal Group and Delphi techniques are similar in their intent but differ in the means by which it is accomplished. Both techniques are intended as problem solving or idea generating exercises where varying forms of expertise or professional judgment must be synthesized into a coherent final product (Delbec et al. 1975).

Delphi is a relatively formal procedure and does not require close physical proximity of the participants. In fact, this aspect of the technique can serve to facilitate participation of expert respondents who cannot come together physically or whose attitudes and opinions may be distracting or antagonistic to one another (Crance, 1987). With the Delphi technique, decision or consensus is reached through a sequential set of questionnaires combined with information summaries and feedback. The process requires a minimum of three groups of individuals as follows: the decision maker or makers who use the product 
of the exercise for their purpose; the staff group that designs the initial questionnaire, summarizes the respondent information and designs subsequent questionnaires; and the respondent group whose expert judgment is used to respond to the questionnaires (Delbec et al. 1975). The Delphi Technique can be rather flexible in its application depending upon the issues to be resolved and the nature of the respondent group.

The Nominal Group Technique is less formal than the Delphi method and does require proximity of all parties. It combines certain aspects of Delphi and Normal InteractiveGroup methods. A Nominal Group follows a specific structure designed to provide definite fact-finding and evaluation phases to the process, assure balanced participation of all individuals, and provide a simple mathematical voting procedure to quantify individual judgments within the group decision (Delbec et al. 1975). The structure used by the Nominal Group to address a problem begins with the silent generation of ideas by each participant, ideas are then compiled and recorded to complete the nominal phase of the exercise. Discussion for clarification and evaluation of all input is followed by voting. The voting is used to mathematically rank or rate the ideas thus providing the group decision (Delbec et al. 1975).

Decision analysis, as described in Howard and Matheson (1968), is a means to simplify complex problems through the use of logical processes. Decision analysis is generally similar to the site selection process used by ESS in that it approaches the solution to a problem by quantifying knowledge pertinent to the issue. When knowledge of the problem is as complete as possible, in the sense that all alternatives and their desirable and undesirable aspects are quantified, the decision becomes one of preference or choice based on known attributes. Both decision analysis in general and the site selection process specifically then provide conceptual and practical methods for measuring or ranking preferences among solutions or sites.

\section{Standardization of the Site Selection Process}

The previous site selection exercises mentioned above have provided valuable lessons for future applications of the method. As this should be a dynamic and flexible process, any standardization of the method should only serve as guidelines to provide a sound, defensible, and consistent means for site selection activities.

The most important part of the process is committee selection. This is the first consideration taken after the need for a site selection study is identified. Committee selection is best accomplished by the cooperation of two entities; the "owner" of the proposed activity for which a site is to be selected, and the person who will serve as the leader or chairperson of the selection committee. There are many considerations that must be addressed in committee selection, size of the committee being of prime importance. It is better to have a small committee whose members have access to various technical expertise than to have a huge and potentially unmanageable committee containing experts in every remotely related field. A committee that is too small may fail to consider or properly address some critical aspect of the site selection or may not have a wide enough range of technical expertise to properly address certain technical aspects of the project. Balance, in numbers and expertise, is very important for the smooth operation of the process. Another aspect of committee selection is proper representation, care must be taken to make sure that all pertinent areas of technical and regulatory expertise are represented. This representation is dependent upon a sound and extensive project description and specification that includes many things such as facility size, type, emissions, support services, and so on. For example, it would be foolish to have a site selection committee without a geologist choosing a site for a project requiring extensive geologic characterization. It is also important to assure that all groups or 


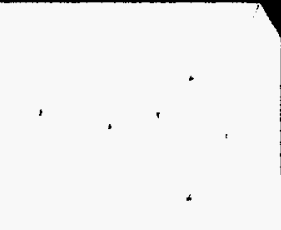


organizations that will actively participate in the planning, construction, operation, or monitoring of the proposed project are either directly or indirectly represented on the site selection committee.

The first step which the assembled committee must take is to identify exclusion criteria. Exclusion criteria can be general or project specific; either way they are considerations that exclude any location from further consideration. Exclusion criteria that apply generally to all projects are things like endangered species impacts, wetlands infringement, waste sites, or research set aside areas. These things preclude the location of any project regardless of its nature. Some exclusion criteria that can often be general, like discharge to a high quality stream, may not apply to a project that has no waste water discharge. Project specific exclusion criteria are those requirements unique to the proposed facility that may dictate where it can or cannot be constructed. For example, depth to ground water may be critical to the project, therefore any area with insufficient depth to ground water would be excluded. After the committee has chosen and reviewed exclusion criteria, the expertise of a drafter versed in Geographic Information Systems (GIS) is required. Maps of the total area to be considered, in our case SRS, are generated showing areas of all the exclusion criteria.

At this point the committee actually chooses potential sites for the proposed action, usually between 5 and 10 different ones. This is done by consensus, often using the GISgenerated maps and an object roughly the size of the area required for development. The number of candidate sites is not limited; however, too many make it a more protracted undertaking. The number of sites chosen is not fixed either. The committee may add or delete sites by consensus at any later point in its considerations. The committee is then often sent off to determine the things within their areas of expertise and interest in the project that should be used for selecting from among the candidate sites. These things will be considered for selection as screening criteria.

Screening criteria are grouped into categories which are weighted by consensus of the committee. For example the categories may be ecology, geology, hydrology, human health, or engineering. However, Human Health and emergency planning should always be considered. Categories are not limited, but an excessive number complicates the weighting and scoring scheme. Screening criteria within the categories are then weighted as to their relative importance within the category. This too is done by committee consensus. An example would be that within the ecology category, terrestrial resources is weighted at $20 \%$, wetlands at $40 \%$ and aquatic resources at $40 \%$. Weighting of screening criteria is apportioned to sum to $100 \%$ within the category and each criterion is allocated a maximum possible score. The same scheme is used for categories, in that the sum of category weights is set to $100 \%$ and categories each are allocated a maximum possible score. The example presented below (Appendix A) will help to clarify the weighting and scoring system. There is nothing to prevent the committee from using a scale of one to ten instead of the 100 point scale, it may be easier for some participants to assign relative raw scores to potential sites on a scale of ten.

After screening criteria and categories are determined and the weighting scheme is agreed upon, individual experts rank the sites for the criteria within their area using literature information, preliminary field observations, and best professional judgment. The committee then meets and all technical experts contribute their rankings. One or two individuals on the committee then compile the numbers and produce the rankings of the candidate sites and present them to the committee. The committee then evaluates the final scores and agrees on a preferred site and one or more alternates. 
An important aspect of the site selection process is that all sites considered in the screening evaluation are potential locations for the proposed project simply because they were chosen after exclusion criteria were defined. The screening process is simply a way of comparing the relative advantage or favorability of the different candidate sites. Because of this, there is often little difference in site scores. This similarity often precludes any rigorous statistical comparison of the sites, although sensitivity analysis (Box et al, 1978) could be performed on the weighting and scoring scheme. It should be remembered however, that site selection as described here is not a statistical exercise but a decision process that depends primarily upon simplicity and best professional judgement. The final recommendation is the responsibility of the committee. A difference in score of a few points between two sites is not necessarily indicative of significant differences among sites. In other words, Site A may score 82 points and Site B may score 79 points, but for reasons of best professional judgment by the committee, Site B may be the preferred site while Site A is the alternative.

The final act of the committee is to approve the draft report that would generally be coauthored by the representative of the organization whose project was being sited and the chairman of the selection committee. The report is then submitted for SRS site review and approval, publication and distribution. These reports usually include the words "preliminary site selection" in the title because they are often done before great amounts of time and money are spent on site characterization. The intention of the site selection process is to minimize unnecessary expenditures of resources on extensive characterization of numerous sites. Using the technical resources available and the simple organization described herein can increase the likelihood of realizing that objective. A generalized flow diagram of the site selection process is shown in Figure 1. 



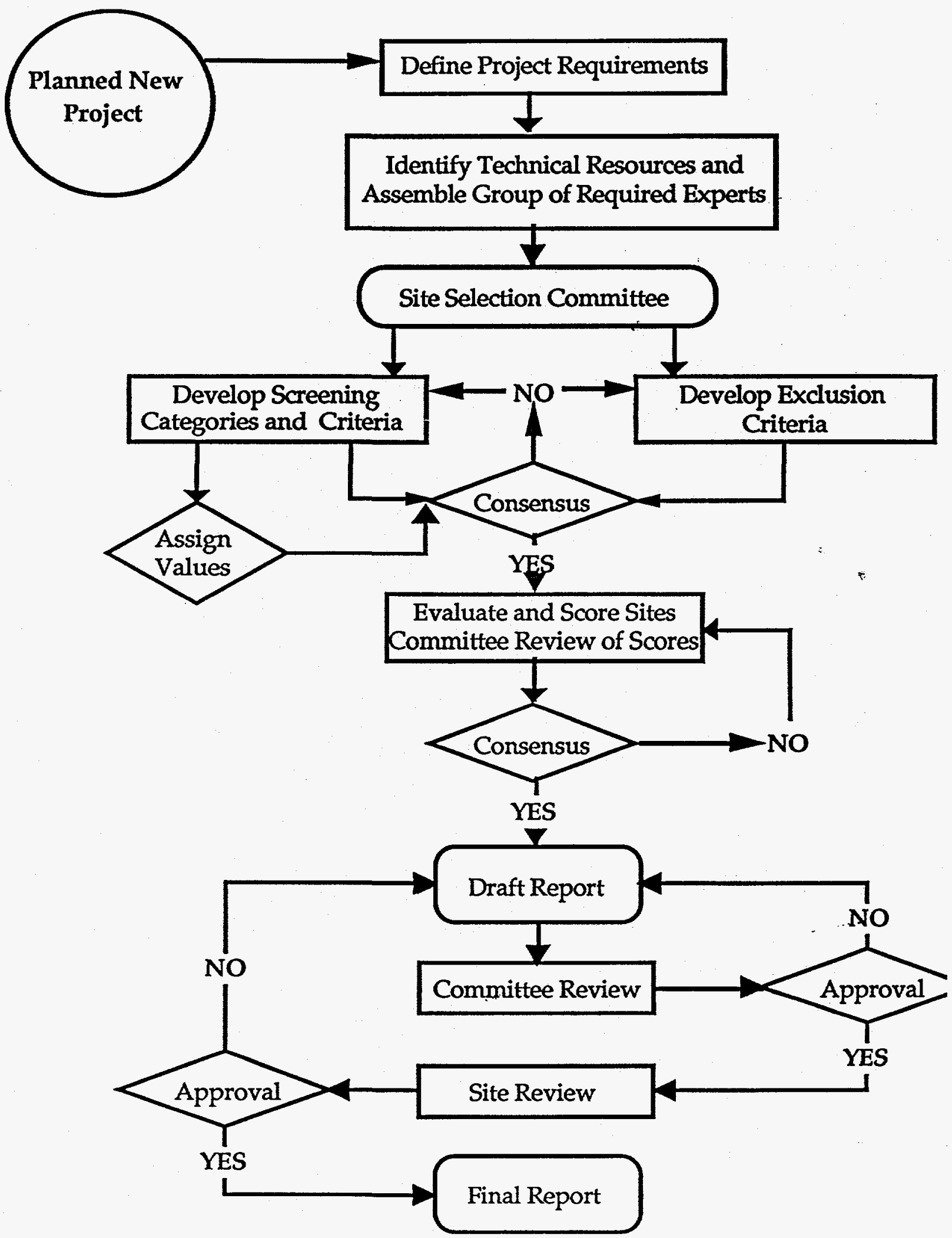

Figure 1. Generalized flow diagram of the site selection process. 


\section{References}

Bean, D. J., H. P. Oslon. Technical Evaluation of Potential Sites for the New Production Reactor at the Savannah River Site (U). WSRC-RP-90-385. Westinghouse Savannah River Company, Aiken, South Carolina. 1990.

Box, E. P., W. G. Hunter, J. S. Hunter. Stastics for Experimenters. John Wiley \& Sons, Inc. New York. 1978.

Crance, Johnie H. Guidelines for Using the Delphi Tecnique to Develop Habitat Suitability Index Curves. Biological Report 82(10.134). National Ecology Center, Division of Wildlife and Contaminant Research, Fish and Wildlife Service, U.S. Department of the Interior, Washington, DC. 1987.

Delbec, A. L., A. H. Van de Ven, D. H. Gustafson. Group Techniques for Program Planning a Guide to Nominal Group and Delphi Processes. Scott, Foresman and Company, Glenview, Illinois. 1975.

DOE SRFO (Department of Energy, Savannah River Field Office). Proposal for the Nuclear Weapons Complex Reconfiguration Site. Aiken, South Carolina. 1991

Howard, R. A., J. E. Matheson. An Introduction to Decision Analysis, in The Principles and Applications of Decision Analysis, Volume I: General Collection. R. A. Howard, J. E. Matheson, eds. Stanford Research Institute. 1968.

US DOE (United States Department of Energy). Invitation for Site Proposals for the Nuclear Weapons Complex Reconfiguration Site. U.S. Department of Energy, Office of the Assistant Secretary for Defense Programs, Washington, D.C. 1991.

Wike, L. D., G. L. Toole, W. L. Specht. Replacement Power Facility Site Selection Report (U). WSRC-RP-92-672. Westinghouse Savannah River Company, Aiken, South Carolina. 1992.

WSRC (Savannah River Technology Center / Environmental Sciences Section). Preliminary Site Selection Report for the New Sanitary Landfill at the Savannah River Site (U). WSRC-RP-92-1397 Rev 1. Westinghouse Savannah River Company, Aiken, South Carolina. 1992. 


\section{Appendix A}

The following example is a fictitious representation of the site selection process at SRS. Organization $\mathrm{A}$ has designed and received permission to build a facility at SRS. The design engineer in charge of project siting approached the Environmental Sciences Section (ESS) of SRTC to help select a site for the new facility. Since the engineer and his group are well prepared, he has a list of all the engineering requirements for the facility. A site selection committee is selected that includes the engineer, a member of ESS, someone from Environmental Protection Department for compliance help, a soils and wetland scientist, a hydrogeologist, a geologist, a GIS/electronic data expert, engineers from Organization $A$, and a representative from DOE.

At the first meeting of the committee, exclusion criteria are selected, the list includes the following group that is generally the norm at SRS:

- Threatened and Endangered Species

- Category I Wetlands and Unavoidable impacts to Category 1 Streams

- NERP Sites

- Reserved for Future Use

- Known Waste Sites

- 100-Year Flood plain

In addition, the following project specific exclusion criteria are added.

- Elevation greater than 250 feet above MSL (Mean Sea Level)

- At least 1 kilometer from L Lake and PAR Pond

- At least 2 kilometers from site boundary

The first meeting ends with directions to the GIS expert to produce a large map of SRS with all the exclusion criteria shown in different colors. The remainder of the group is charged with developing screening criteria and categories.

At the next meeting the group chooses screening criteria groups and weights as follows:

- Ecology 30

- Geology/Hydrology $\quad 30$

- Engineering 25

- Security 15

Difficulties with the GIS process postponed the availability of a map so the committee continued with the screening criteria and established the specific criteria and weights within the groups as shown in Table 1.

By the next meeting the map was available. The group found an object of the approximate scale area required for the project and began choosing candidate sites. A total of 10 preliminary sites were chosen and the committee agreed to visit all of them as a group the following day. After the field trip the committee narrowed its candidate sites to six and agreed to meet in two weeks with raw scores for all sites. At the next meeting the committee produced the raw scores for the six candidate sites as shown in Table 2.

These raw scores were then multiplied by the category weights to determine the weighted category score for each site. For example, Site 1 had an ecology raw score of 75 and the category weight is 30 so the weighted score would be .3 times 75 or 22.5 . The weighted scores were summed for each site resulting in the values in Table 3. 
Ecology

Aquatic Resources

Wetland Resources

Terrestrial Resources

Geology/Hydrology

Depth to Groundwater

Depth to Basement

Soil Stability

Slope

Engineering

Distance to Road

Distance to Rail

Distance to Water/Sewer

Distance to Power

Security

Distance to Site Boundary

Distance to Other Facilities

Distance to WSI Heliport
30

30

$$
\begin{gathered}
40 \\
40 \\
20 \\
100
\end{gathered}
$$

30

25

20

25

25

$\frac{25}{100}$

\section{5}

25

25

25

15

Total

100

Table 1. Screening Criteria and Weights

\begin{tabular}{lllllll} 
Site & 1 & 2 & 3 & 4 & 5 & 6 \\
\hline Ecology & 35 & 40 & 25 & 30 & 22 & 37 \\
Aquatic Resources & 25 & 25 & 35 & 38 & 20 & 15 \\
Wetland Resources & 15 & 15 & 20 & 10 & 15 & 12 \\
Terrestrial Resources & 75 & 80 & 80 & 78 & 57 & 64 \\
& & & & & & \\
Geology/Hydrology & 30 & 30 & 30 & 30 & 30 & 30 \\
$\begin{array}{l}\text { Depth to Groundwater } \\
\text { Depth to Basement }\end{array}$ & 20 & 15 & 25 & 25 & 10 & 18 \\
Soil Stability & 10 & 15 & 10 & 20 & 16 & 20 \\
Slope & 15 & 22 & 25 & 18 & 11 & 17 \\
& 75 & 82 & 90 & 93 & 67 & 85 \\
Engineering & 12 & 20 & 16 & 22 & 25 & 18 \\
Distance to Road & 20 & 23 & 12 & 10 & 25 & 18 \\
$\begin{array}{l}\text { Distance to Rail } \\
\text { Distance to Water /Sewer }\end{array}$ & 25 & 20 & 15 & 22 & 25 & 22 \\
Distance to Power & 13 & 15 & 22 & 25 & 16 & 20 \\
& 70 & 78 & 65 & 79 & 91 & 78 \\
Security & & & & & & \\
Distance to Site Boundary & 50 & 40 & 30 & 44 & 37 & 29 \\
Distance to Other Facilities & 12 & 22 & 29 & 17 & 30 & 22 \\
Distance to WSI Heliport & 18 & 18 & 13 & 20 & 15 & 16 \\
& 80 & 80 & 72 & 81 & 81 & 67
\end{tabular}

Table 2. Raw Scores 


$\begin{array}{lcccccc}\text { Site } & 1 & 2 & 3 & 4 & 5 & 6 \\ \text { Ecology } & & & & & & \\ \text { Geology/Hydrology } & 22.5 & 24.0 & 24.0 & 23.4 & 17.1 & 19.2 \\ \text { Engineering } & 22.5 & 24.6 & 27.0 & 27.9 & 20.1 & 25.5 \\ \text { Security } & 17.5 & 19.5 & 16.3 & 19.8 & 22.8 & 19.5 \\ \text { Total } & 12.0 & 12.0 & 10.8 & 12.2 & 12.2 & 10.1 \\ & \mathbf{7 4 . 5} & 80.1 & \mathbf{7 8 . 1} & \mathbf{8 3 . 3} & \mathbf{7 2 . 2} & \mathbf{7 4 . 3}\end{array}$

Table 3. Weighted Scores

The consensus of the committee was to recommend Site 4 as the preferred site. There was some discussion about whether to designate Site 2 or Site 3 as the alternate site. Consensus was reached, and Site 2 was designated as the alternate site. The committee adjourned with the understanding that all members would see draft copies of the site selection report to be authored by the committee chairman and the senior Organization A representative. A tentative meeting was scheduled for one month later to discuss the draft and finalize the report. The report was accepted and submitted for approval and publication. After the report was approved, Organization A began the detailed characterization of Site 4. 